\title{
Differences in donor compatibility for fresh and freeze-dried homologous platelet rich plasma studied using crossmatch test
}

\author{
Nandini Anindita Sumitro ${ }^{1}$, Wiwin Winda Kusumadewi ${ }^{1}$, Fitri Yuniawati $^{1}$, Naila Amalia ${ }^{2}$, Hendrawati Hendrawati ${ }^{3}$, \\ and Kwartarini Murdiastuti ${ }^{3}$ \\ ${ }^{1}$ Clinical Dentistry Program, Faculty of Dentistry, Universitas Gadjah Mada, Yogyakarta, Indonesia \\ ${ }^{2}$ Blood Transfusion Unit, Palang Merah Indonesia, Yogyakarta, Indonesia \\ ${ }^{3}$ Department of Periodontology, Faculty of Dentistry, Universitas Gadjah Mada, Yogyakarta, Indonesia
}

\begin{abstract}
Platelet-rich plasma (PRP) rich in growth factors has evolved as an important therapy for periodontal tissue regeneration. A healthy blood donors obtained for homologous PRP (h-PRP). The Freezedrying h-PRP sample provides an effective method to ensure a longer shelf-life. The h-PRP samples are subjected to crossmatch testing in clinics to prevent any immune response in recipients. The present study aimed to evaluate the differences in donor compatibility on crossmatch test results towards fresh and freezedried h-PRP (FD h-PRP). This was a laboratory experiment, h-PRP prepared according to the protocol of blood bank, and 40 recipients blood samples divided into two groups, fresh h-PRP (control group) and FD h-PRP. The crossmatch test was performed to evaluate h-PRP compatibilities by using the gel-test method. The data were analyzed using the chi-square test. The results of the study showed that the crossmatch test on FD h-PRP samples was $100 \%$ compatible and could increase the compatibility results of the donor. the FD h-PRP was safe to become donors and clinical applications.
\end{abstract}

\section{Introduction}

Platelet-rich plasma (PRP) is plasma sample rich in platelets, growth factors, chemokines, cytokines and other proteins. It finds wide applications in medical field, especially in dentistry. It is most commonly utilized in combination with other materials and used as graft to assist in formation of new bone and regeneration of periodontal tissue. The main goal of periodontal disease treatment is to regenerate the periodontal tissue and compensate for the loss due to periodontal disease by supporting new bone formation $[1,2]$. The periodontal tissue regeneration has attracted several research efforts focusing on the disease treatment via stimulation of new bone formation and use of new attachment apparatus involving addition of biological mediators. Growth factors are examples of biological mediators that are known to be highly effective in wound healing and regeneration. PRP is used as a rich source of growth factors and administered to infected area $[3,4]$.

Autologous platelet-rich plasma (A-PRP) is a plasma product produced from the patient's own blood (autologous), which contains high concentration of platelets. However, the use of A-PRP in periodontal tissue regeneration has been reported to show variable treatment outcomes owing to variability in platelet amounts. This variability in platelet amounts is generally contributed by various conditions in patients, such as poor medical history, multi-drug therapy, or hematological disorder. Such patients are not ideal candidates for A-PRP therapy. Besides this, the availability of small blood volumes often results in adverse effects, especially in conditions requiring repeated treatments $[5,6]$.

Homologous PRP or allogeneic PRP is PRP sample obtained from healthy blood donors. In the present study, h-PRP was obtained as a by-product from the blood bank of Palang Merah Indonesia (PMI). The use of h-PRP in dentistry offers several benefits like ease of preparation, higher platelet content than the required therapeutic ratio, and easy availability [5]. Fresh h-PRP is PRP obtained by centrifugation of blood in liquid form [7]. Fresh h-PRP samples used in periodontal treatment are obtained from healthy blood donors screened properly in blood banks. Growth factors present in fresh h-PRP generally have short half-life. The shortest time duration for which h-PRP can be stored at room temperature is $48 \mathrm{~h} \mathrm{[8] \text {. }}$

As an alternative, freeze-drying of h-PRP is recommended for long term storage. The freeze-dried $h-$ PRP samples offer advantages of higher growth factor content and easy availability when required $[9,10]$. Besides this, the freeze-drying process of h-PRP results in protein reduction, denaturation, and undetectable antibody. This reduces the risk of rejection or elicitation of immune response [11]. The use of h-PRP therapy in clinics generally involves crossmatch testing. The purpose of crossmatch test is to detect the presence of anti-HLA on the donor's platelets in order to avoid any

* Corresponding author: kmurdiastuti@ugm.ac.id 
risk of immune response against h-PRP and also to ensure maximum benefits of h-PRP for the recipients [12]. The present study aimed to evaluate the differences between donor compatibility on crossmatch test results towards fresh and freeze-dried h-PRP.

\section{Materials and methods}

\subsection{PRP sample preparation}

The present study was a laboratory experiment and all the eperimental procedures were approved by the Ethics Committee, Faculty of Dentistry, Universitas Gadjah Mada, Indonesia (registration number 0029/KKEP/FKG-UGM/EC/2019). Homologous PRP was obtained in double bags from the blood bank of PMI. As per the guidelines of transfusion service standard, all the donors fulfilled the criterias of selection and were tested for Transmitted Infection Through Blood Transfusion (IMLTD). The whole blood sample was centrifuged in RC KUBOTA 9942 centrifuge at $1000 \mathrm{rpm}$ for $15 \mathrm{~min}$ at $22{ }^{\circ} \mathrm{C}$ to separate platelet-rich plasma (PRP) and red blood cells (RBCs). An average of $100 \mathrm{~mL}$ to $120 \mathrm{~mL}$ PRP was obtained per bag based on $\mathrm{ABO}$ blood groups. h-PRP samples were divided into two groups, fresh h-PRP and freeze-dried h-PRP.

\subsection{Freeze-drying procedure}

For freeze-drying, h-PRP samples were frozen at $-40{ }^{\circ} \mathrm{C}$ for $12 \mathrm{~h}$. The frozen samples were freeze-dried using a freeze dryer for $48 \mathrm{~h}$ (Freeze Dryer Modulyo, Edwards). Further, a mortar and pestle was used for grinding these samples, which were later passed through a 60-mesh filter for filtration inside a laminar flow cabinet. The samples are stored in a microtube and then sterilized using gamma ray radiation then stored at room temperature.

\subsection{Crossmatch test}

For crossmatch testing, blood cell samples for 40 recipients were obtained from the blood bank at PMI. For each group, fresh h-PRP group and freeze-dried hPRP (FD h-PRP) group, 20 samples consisting of all blood types (A, B, AB, and $\mathrm{O}$ ) were used. Gel based method was used for compatibility testing. Blood group and rhesus tests were performed before crossmatch test. The donor number identity and recipient identity were indicated on the comb card (recipient name, blood type, date, and minor). For compatibility test, a $0.8 \%$ suspension of the recipient red cells was prepared by mixing $10 \mu \mathrm{L}$ of red blood cells in $1 \mathrm{ml}$ of low ionic strength solution, LISS (ID diluents). Following this, 50 $\mu \mathrm{L}$ of the recipient red cell suspension was transferred into a micro tube and $25 \mu \mathrm{L}$ of the donor serum was added to it. The sample was incubated at $37{ }^{\circ} \mathrm{C}$ for $15 \mathrm{~min}$ in an incubator (ID-Incubator $37 \mathrm{~S} \mathrm{II).} \mathrm{Further,}$ the sample was centrifuged using ID centrifuge (Grifols Spin 12) and results were analyzed macroscopically. Freeze-dried h-PRP was rehydrated using phosphate buffer saline at $\mathrm{pH} 7.4$ (PBS). To avoid any changes in components, the weight heading was adjusted by taking weight before freeze-drying. Absence of any agglutination indicated the compatibility of the donor blood with the recipient, and thus suitability for transfusion. In comparison to this, a crossmatch was indicated by the presence of RBC pellets at the bottom of micro tube with no aggregates in the gel matrix.

\section{Results and discussion}

Periodontal disease treatment using PRP therapy involves introduction of number of antigens and living cells into the recipient's body. Platelets are generally small enucleated cell fragments that play pivotal role in sustenance of hemostasis and prevention of blood loss. Platelets are characterized by the presence of complex surface antigens, including Human Platelet Alloantigen (HPA), Human Leukocyte Antigen (HLA), and blood group antigen $\mathrm{ABO}$. These antigens are known to be very important in blood transfusion process [13, 14]. Generally, an immune competent recipient will show an immune response against the donor antigens (all immunization). Such a response can even occur in case of fresh h-PRP samples. Several studies have reported clinical applications of h-PRP in various diseased conditions like osteoarthritis, periodontal disease, and others $[5,7,15]$. Despite the presence of same blood type in the recipient and donor, an incompatibility is still possible in the examination of fresh h-PRP crossmatch test. This can be contributed by mistake in detection of $\mathrm{ABO}$ blood type due to failure in examination and distribution of wrong labels on blood bags. The mistake in detection of donor's blood type $\mathrm{ABO}$ system can occur due to the presence of weak antigen in the recipient's red blood cells that can either result in low levels of antibody insufficient to be detected or complete absence of antibody production. Such conditions make the detection of antigens quite difficult in elderly persons, patients with malignancy, patients consuming immunosuppressant medicines, and patients with bone marrow transplantation $[16,17]$.

The present study involved the use of fresh h-PRP and freeze dried h-PRP. Fresh h-PRP and freeze dried hPRP samples were prepared using standard protocol. Cross-match tests were performed using gel method with twenty recipients per group. The results of crossmatch test for the fresh h-PRP group with twenty blood recipient samples are summarized in Table 1 . According to Table 1, the results of donor compatibility test showed that $100 \%$ donors were compatible with all blood types. All the blood samples were obtained from the blood bank of PMI and all the recipients were physically healthy as they all fulfilled the selection criteria specified by the blood bank. Both these factors contributed to the $100 \%$ compatibility observed in case of fresh h-PRP. The usage of h-PRP was a form of the blood component transplantation. 
Table 1. The blood type tabulation with the crossmatch test of fresh treatment

\begin{tabular}{lcccccc}
\hline & \multicolumn{5}{c}{ Blood Type } & Total \\
& $\mathrm{A}$ & $\mathrm{AB}$ & $\mathrm{B}$ & $\mathrm{O}$ & \\
\hline $\begin{array}{c}\text { Blood cells } \\
\begin{array}{c}\text { agglutination Compatible } \\
\text { (Fresh) }\end{array}\end{array}$ & 5 & 5 & 5 & 5 & 20 \\
& $100 \%$ & $100 \%$ & $100 \%$ & $100 \%$ & $100 \%$ \\
\hline
\end{tabular}

The results for compatibility test for twenty recipient blood samples in freeze-dried h-PRP group are summarized in Table 2. Freeze-dried h-PRP donors were found to be $100 \%$ compatible with all blood types. The freeze-drying process generally aims to preserve the growth factor contents in PRP. Several studies have reported that h-PRP samples retain growth factors post preparation [12]. However, freeze-drying h-PRP might affect the levels of some of the proteins owing to factors like heat-sensitive nature of plasma proteins and allergic proteins. This heat sensitivity might result in denaturation of proteins during freeze-drying process, and thus absence of antibody detection. The proteins are generally present as transmembrane proteins in the lipid bilayer membrane, which helps to maintain the biological function and membrane physiology. The membrane might experience a series of chemical and physical changes (transition phase). During freezedrying, the platelet membrane lipids experience a transition phase which can cause ion leakage through the membrane. In addition to this transition phase, a cold condition can also induce phase lateral separation of the membrane components, which can result in micro domain aggregation and platelet activation. During the process of drying, the membrane compensates for the loss of hydrogen bond on water $\left(\mathrm{H}_{2} \mathrm{O}\right)$ by forming a hydrogen bond with another molecule. This produces between-molecules interaction, in which inside the protein can be compensated by proteins interaction and therefore can cause the protein aggregation or denaturation [18].

Table 2. The blood type tabulation with the crossmatch test of the freeze-dried treatment

\begin{tabular}{ccccccc}
\hline & \multicolumn{5}{c}{ Blood Type } & \multirow{2}{*}{ Total } \\
\hline Blood cells & $\mathrm{A}$ & $\mathrm{AB}$ & $\mathrm{B}$ & $\mathrm{O}$ & \\
$\begin{array}{c}\text { agglutination } \\
\begin{array}{c}\text { (Freeze-dried } \\
\text { treatment) }\end{array}\end{array}$ & 5 & 5 & 5 & 5 & 20 \\
\hline
\end{tabular}

Crossmatch test results were statistically analyzed using chi-square test. The results for chi-square analysis for both the groups, fresh h-PRP and freeze-dried PRP are summarized in Table 3.

Table 3. Chi-Square test

\begin{tabular}{|c|c|c|c|c|c|c|}
\hline & \multicolumn{6}{|c|}{ Treatment } \\
\hline & & & $\begin{array}{c}\text { Freeze- } \\
\text { dried }\end{array}$ & Fresh & Total & Sig \\
\hline Blood Cells & Comnatible & $\mathrm{N}$ & 20 & 20 & 40 & \\
\hline Agglutination & Compatıble & $\%$ & $100 \%$ & $100 \%$ & $100 \%$ & - \\
\hline Total & & $\begin{array}{l}\mathrm{N} \\
\%\end{array}$ & $\begin{array}{c}20 \\
100 \%\end{array}$ & $\begin{array}{c}20 \\
100 \%\end{array}$ & $\begin{array}{c}40 \\
100 \%\end{array}$ & \\
\hline
\end{tabular}

Data for both fresh treatment and freeze-dried treatment showed $100 \%$ compatibility. Chi-square analysis did not produce negative significance values. All these results suggested that crossmatch test on freeze-dried hPRP samples was able to improve the results of donor compatibility. These results further established the safety of freeze-dried h-PRP for clinical application. Thus, crossmatch test can be used as an important tool for compatibility testing of freeze-dried h-PRP samples to ensure safe and efficient application of h-PRP therapy for various diseases.

\section{Conclusion}

The results of the present study established the suitability and safety of freeze-dried h-PRP for clinical applications.

This research was funded by Rekognisi Tugas Akhir (RTA) Universitas Gadjah Mada, Yogyakarta, Indonesia.

\section{References}

1. F. Creeper, S. Ivanovski, Oral Diseases, 18, 494500 (2012)

2. C.E. Markopoulou, P. Markopoulous, S.E. Dereka, E. Pepelassi, I.A. Vrotsos, J Musculoskelet Neuronal Interact., 9, 3, 167-172 (2009)

3. J.D. Bashutski, R.M. Eber, J.S. Kinney, E. Benavides, S. Maitra, T.M. Braun, W.V. Giannobile, L.K. McCauley, N Eng J Med, 363, 25, 2396-2405 (2010)

4. W.V. Giannobile, K.F. Al-Shammari, D.P. Sarment, Periodontology 2000, 31, 125 (2003)

5. Bottegoni C., Dei Giudici L., Salvemini S., Chiurazzi E., Bencivenga R. and Gigante A., Ther Ad Musculoskel Dis, 8, 2, 35-41 (2016)

6. M.J. Martinez-Zapata, A. Marti-Carvajal, I. Sola, I. Bolibar, J.A. Exposito, Transfusion Practice, 49, 44-56 (2009)

7. R. Prabhu, C. Vijayakumar, C.A. Bosco, K. Balagurunathan, R. Kalairasi, K. Venkatesa, E.S. Raja, Cureus 10, 2, (2018)

8. Y. Shiga, et al., Sci. Rep., 6, 36715 (2016)

9. K. Murdiastuti, F. Yuniawati, N. Purwanti, D. Herawati, AIP Conference Proceedings, 2099, 020015 (2019)

10. L. Pan, Z. Yong, K.S. Yuk, K.Y. Hoon, S. Yuedong, J. Xu, Aesthetic Plast Surg 40, 157-163 (2016)

11. A.P. Bode, T.H. Fischer, Blood Substitutes, and Biotechnology, 35, 1, 125-133 (2007)

12. Yuan Shan., Pretransfusion Compatibility Testing, Available online at http://pathology.ucla.edu/workfiles/Education/Tra nsfusion\%20Medicine/PretransfusionCompatibility-Testing.pdf (2011)

13. P. Rozman, Transplant Immunology, 10,165-181 (2002)

14. Z-Y. Zang, et al., Cell Transplant., 22, 175-187 (2013) 
15. B. Ince, M.E.C. Yildirim, M. Dadaci, M.C. Avunduk, N. Sacavi, Aesth Plast Surg., 42, 297303 (2018)

16. M.K. Fung, K.A. Downes, I.A. Shulman, Arch Pathol Lab Med, 13, 909-916 (2007)

17. R. Syafitri, Kasus-kasus Rujukan Imunohematologi, available online at http://ppds.fk.ub.ac.id/wpcontent/uploads/2016/04/Pem-Uji-Silang-SerasiPermasalahannya-presentasi-terbaru-24-Sept-12presentasi-revisi.pdf (2016) [in Bahasa Indonesia]

18. J.H. Crowe, F. Tablin, W.F. Wolkers, K. Gousset, N.M. Tsvetkova, J. Ricker, Chemistry and Physics of Lipids, 122, 41-52 (2003) 